\title{
Comparing of Data Collection for Network Level Pavement Management of Urban Roads and Highways
}

\author{
Hui Wang $\mathbb{D}^{1}{ }^{1}$ Zhoucong $\mathrm{Xu}^{2}$ and Lei Yue ${ }^{3}$ \\ ${ }^{1}$ Key Laboratory of New Technology for Construction of Cities in Mountain Area, Chongqing University, Chongqing, China \\ ${ }^{2}$ China Merchants Chongqing Communications Technology Research \& Design Institute Co., Ltd., Chongqing, China \\ ${ }^{3}$ The Key Laboratory of Road and Traffic Engineering, Ministry of Education, Tongji University, Shanghai 201804, China
}

Correspondence should be addressed to Hui Wang; mickysophy@cqu.edu.cn

Received 24 February 2019; Revised 2 October 2019; Accepted 14 October 2019; Published 6 January 2020

Academic Editor: Juan C. Cano

Copyright (C) 2020 Hui Wang et al. This is an open access article distributed under the Creative Commons Attribution License, which permits unrestricted use, distribution, and reproduction in any medium, provided the original work is properly cited.

\begin{abstract}
Pavement condition data are collected by agencies to support pavement management system (PMS) for decision-making purpose as well as to construct performance model. The cost of pavement data collection increases with the increase of survey frequencies. However, a lower monitoring frequency could lead to unreliable maintenance decisions. It is necessary to understand the influence of monitoring frequencies on maintenance decision by considering the reliability of performance prediction models. Because of different maintenance conditions of urban roads and highways, their performance show different trends. In this paper, the influence of pavement monitoring frequency on the pavement performance models was investigated. The results indicate that low collection frequencies may result in delay in maintenance action by overestimating pavement performance. The collection frequency for Pavement Condition Index (PCI) can be reduced without compromising the accuracy of performance model, more work should be done to ensure the PCI data quality, thus to guarantee the rationality of maintenance decisions. Effect of frequency reduction on pavement performance (IRI) models of urban roads seems greater than on pavement performance (IRI) models of highways, which may lead to heavier monitoring work for urban roads management. This paper provided an example which demonstrated how a comparative analysis can be performed to determine whether the current data collection plan can provide sufficient data for time series analysis.
\end{abstract}

\section{Introduction}

Pavement condition data are collected periodically by agencies and are used to construct pavement performance models, perform cost-effectiveness analysis, conduct maintenance, rehabilitation analysis, etc. Due to limited budgets and different response requirements, agencies monitor pavement condition at 1-, 2- or 3-year frequencies [1]. IRI (international roughness index) and rut depth data are not recommended to be collected annually on county roads for lower traffic volumes [2]. IRI is widely accepted and used for evaluating pavement condition, establishing performance models and performing cost-effectiveness analysis of maintenance strategies [3-6]. However, it is proved that IRI cannot be a unique predictor of pavement condition ratings with $41 \%$ of the variation in PCI (pavement condition index) remains unaccounted by IRI [7]. Haider et al. found that more frequent data collection for image-based methods (for PCI collection) can reduce the associated risk in performance prediction and thus be more effective for better decision making for pavement management [8]. As PCI is an image based index, the accuracy of PCI mainly depends on the image quality. Moreover, systematic and random errors can highly distort some output parameters of PMS (pavement management system), even in error ranges that may be considered acceptable in practice [9]. IRI and PCI are two common used performance indices to characterize pavement performance at both network-level and project-level for both urban roads and highways $[5,6,9-12]$.

IRI is calculated from surface profile in longitudinal direction by the quarter-car model [28]. PCI is calculated by pavement distress ratio, which is a function of types of distresses, severity levels and weight. The range of PCI is from 0 to 100 , with 100 indicating a pavement surface is free of distress. IRI is also the most frequently collected pavement condition data by highway agencies in the United States $[14,15]$. Therefore, many studies utilized IRI to construct performance models and perform further analyses $[13,16]$. It is necessary for highway agencies to understand the source of errors for IRI and 
its influence on performance evaluation. Some of the previous studies were conducted to investigate the source of uncertainty on IRI from the perspectives of collection and calculation methods [17-21]. And some of other studies even questioned the use of this index for road quality evaluation $[22,23]$.

Besides data accuracy, the number of data samples is also responsible for the reliability of performance prediction. The number of data samples is associated with the pavement monitoring frequencies. Haider et al. found that the frequency of condition data collection has a significant effect on the performance prediction, higher variability in the data will introduce higher Squared Error (SE) in the fitted model, and data collection frequency can be decreased with higher data accuracy [24]. Xu and Tsai studied the influence of equal time interval and unequal time interval under the same monitoring frequency on prediction of pavement service life, they found the estimated accuracy of pavement service life would be significantly improved for unequal interval monitoring ways compared to that of equal interval monitoring ways under the same monitoring frequency $[25,26]$.

Subject to different traffic conditions, data survey methods of urban roads and highways are different. Highway performance indices including IRI, PCI, and RDI are investigated during the daytime with high speed. However, IRI surveys for urban roads have to be done during the night to avoid traffic congestions, and PCI surveys have to be done at a low speed during the daytime. The agencies need to understand how the difference in data collection frequencies may influence the pavement performance model. With this knowledge, agencies can optimize the data collection plans. Thus they can reduce the frequency without compromising the preciseness and accuracy of analysis. The objective of this study is to compare the influence of data collection frequency on performance models of urban roads and highways. Pavement condition index (PCI), international roughness index (IRI) are utilized for constructing the performance models. As performance models have the potential to change to different deterioration rate with the changes in data collection method, history data collected by the same instrument are used in this paper.

\section{Data Preparation}

2.1. Pavement Condition Data. Road Administration Bureau of Shanghai has been collecting pavement condition data at the network level since 2004. By the end of 2017, the total number of urban road sections managed had been 5225, covering $4,873.361 \mathrm{~km}$, and the total number of highways managed had been 9446 , covering $13,292.397 \mathrm{~km}$. Urban roads are classified into four different types, consisting of high-speed, arterial road, subsidiary road, and branch roads, depending on the speed limits, geometrics, etc. High-speed and arterial roads are surveyed and evaluated annually; the survey round of subsidiary and branch roads take 3 years. Highways are classified into four different types, consisting of high-speed, grade-one, grade-two, and grade-three.

The maintenance action may significantly change the shape of performance models. Therefore, only sections with no rehabilitation records are selected in this study. However, due to the lack of routine maintenance records, it is hard to determine whether there are routine maintenance activities during the entire monitoring period. So, the change of performance condition index within these sections may be caused by either routine maintenance or test errors. In order to perform the time-series analyses, sections with monitoring period of at least 8 years and the number of surveys for at least 4 were selected to include sufficient sample data for analysis. Finally, 14 urban road sections and 11 highway sections were selected from the two databases of Pavement Management Systems (PMSs). Table 1 lists the inventory of the selected pavement sections. The detailed data are listed in the tables of the appendix (Tables 2-5).

Besides, we selected 2922 road sections in LTPP database to study this influence on IRI. 2518 sections unable to reflect performance decay are removed as the IRI value has been below two throughout the data collection cycle or the amount of data is less than three.

2.2. Performance Model. Commonly used linear relationship and exponential function [27] are considered due to its simplified form and the short time span data in this study. In linear model, slope indicates the general change of performance index over ages. In terms of PCI, slope less than zero indicates PCI decreases as the pavement age increases. In terms of IRI, slope greater than zero indicates IRI increases as the pavement age increases. In this study, linear model is expressed in Equation (1), exponential function is expressed in Equation (2).

$$
\text { Index }=k \cdot A g e+c,
$$

where $k$ is the slope and $c$ is the intercept of the performance model.

$$
\text { Index }=a \cdot \exp (b \text { Age }),
$$

where, $a$ and $b$ are the coefficients of performance model; Age represents pavement age.

\section{Influence of Data Collection Frequency on Performance Model}

3.1. $R$ Square Performance Model of IRI. Changes of $R$ square of IRI models for urban roads and highways are shown in Figure 1.

Figures 1(a) and 1(b) show $R$ square values of IRI models for urban roads are all lower than 0.5 , and positive and negative correlations are half-and-half. There seems no regular pattern for urban roads, and the nonlinearity of the pavement condition data is visible. Figures $1(\mathrm{c})$ and $1(\mathrm{~d})$ show that $R$ square values of IRI models for highway increase with the decrease of collection frequency with higher original $R$ square value, but get an inverse trend with lower original $R$ square value. Figures $1(\mathrm{e})$ and 1 (f) show that mostly $R$ square values of IRI models increase with the decrease of collection frequency, which may be due to the amount of the data.

Figure 1 also illustrates $R$ square values have little difference between linear or exponential models. So only linear model is selected for further trend study. 
TABLE 1: Inventory of selected pavement sections of urban roads.

\begin{tabular}{|c|c|c|c|c|c|c|}
\hline \multirow[b]{2}{*}{ Data source } & \multirow[b]{2}{*}{ Section id } & \multirow[b]{2}{*}{$\begin{array}{c}\text { Monitoring } \\
\text { period (Years) }\end{array}$} & \multirow[b]{2}{*}{$\begin{array}{l}\text { Collection } \\
\text { records }\end{array}$} & \multirow[b]{2}{*}{$\begin{array}{l}\text { Section length } \\
\text { (meters) }\end{array}$} & \multicolumn{2}{|c|}{ Collection frequency } \\
\hline & & & & & $\begin{array}{c}\text { Original frequency } \\
\text { (year/time) }\end{array}$ & $\begin{array}{l}\text { Reduced frequency } \\
\text { (year/time) }\end{array}$ \\
\hline \multirow{14}{*}{$\begin{array}{l}\text { Urban road } \\
\text { sections }\end{array}$} & JAS000004325 & 8 & 8 & 422 & 1 & 2 \\
\hline & JAS000004441 & 8 & 8 & 238 & 1 & 2 \\
\hline & HPS000010501 & 8 & 8 & 83 & 1 & 2 \\
\hline & HPS000010493 & 8 & 8 & 85 & 1 & 2 \\
\hline & HKS000003011 & 8 & 8 & 670 & 1 & 2 \\
\hline & HKS000003029 & 8 & 8 & 245 & 1 & 2 \\
\hline & XHS000007879 & 8 & 8 & 186 & 1 & 2 \\
\hline & XHS000007880 & 8 & 8 & 323 & 1 & 2 \\
\hline & CNS000000899 & 8 & 8 & 575 & 1 & 2 \\
\hline & CNS000000821 & 8 & 8 & 364 & 1 & 2 \\
\hline & YPS000014463 & 8 & 8 & 319 & 1 & 2 \\
\hline & YPS000014411 & 8 & 8 & 492 & 1 & 2 \\
\hline & YPS000014328 & 8 & 8 & 439 & 1 & 2 \\
\hline & YPS000013433 & 8 & 8 & 440 & 1 & 2 \\
\hline \multirow{11}{*}{$\begin{array}{l}\text { Highway } \\
\text { sections }\end{array}$} & S121310115 & 10 & 10 & 8300 & 1 & 2 \\
\hline & X005310115 & 10 & 8 & 1230 & 1.25 & 2.5 \\
\hline & X009310115 & 10 & 10 & 8760 & 1 & 2 \\
\hline & X012310115 & 10 & 8 & 1960 & 1.25 & 2 \\
\hline & X030310115 & 10 & 9 & 6710 & 1.11 & 2 \\
\hline & X572310115 & 10 & 10 & 5440 & 1 & 2 \\
\hline & X574310115 & 10 & 10 & 1095 & 1 & 2 \\
\hline & X579310115 & 10 & 7 & 2400 & 1.43 & 2.5 \\
\hline & X581310115 & 10 & 10 & 7100 & 1 & 2 \\
\hline & X583310115 & 10 & 10 & 2603 & 1 & 2 \\
\hline & X585310115 & 10 & 10 & 780 & 1 & 2 \\
\hline
\end{tabular}

3.2. Performance Deterioration Trend of IRI. Figures 2 and 3 illustrated the results of matched pair tests for the slopes and the intercepts of the linear models of IRI for original collection frequency and reduced collection frequency. The slope indicated the general trend of change of performance index. The average value of means, the average value of differences, the $95 \%$ upper bond, and the $95 \%$ lower bond are marked with red dotted line in Figures 2 and 3.

Figures 2(a), 2(b), 3(a), and 3(b) imply that the slopes of the linear models determined by original collection frequency may be higher than reduced collection frequency, which means reduction of data collection frequency may lead to an underestimation of pavement roughness condition. Figures 2(c) and 3(c) show an inverse trend that the slopes of the linear models determined by original collection frequency is lower than reduced collection frequency. Although data with the max IRI value below two are removed, most road sections from LTTP data have a good level of roughness, which is different from the data from PMS of Shanghai.

The performance rate of IRI change of urban roads is more discrete than the performance rate change of highways, which indirectly reflects the limitations of IRI data in urban road applications.

3.3. $R$ Square for Performance Model of PCI. Changes of $R$ square of PCI models for urban roads and highways are shown in Figure 4 . The spots above the equity line indicate $R$ square value increased by reducing the collection frequency, whereas those spots below the equity line indicate the contrary trend.

Seen from Figure 4 , the changes of $R$ square values of linear and exponential models are similar for both urban roads and highways. The $R$ square values increased with the decrease of collection frequency with higher original $R$ square value (i.e., $R$ square greater than 0.5 ). And there is no consistent trend of $R$ values with lower original $R$ square value (i.e., $R$ square less than 0.5), which implies there is no obvious influence of collection frequency on construction of performance model with lower original $R$ square value. This means the increase of data samples may decrease $R$ square depending on data variability, the decrease of collection frequency may not necessarily compromise the precision and accuracy of performance model. Comparing the data with higher original $R$ square value to the data with lower original $R$ square value, it is indicated that ensuring the data quality is much more necessary than increasing the collection frequency for pavement performance models construction. It was also found that there was no significant change of $R$ square between two models (linear model and exponential model).

For urban roads, performance model of PCI based on higher frequency is more proper for a certain project with clear maintenance history but may be inappropriate for net level management. For performance model construction and evaluation on average condition in a certain area, data collection frequency can be reduced to 2-3 years. 


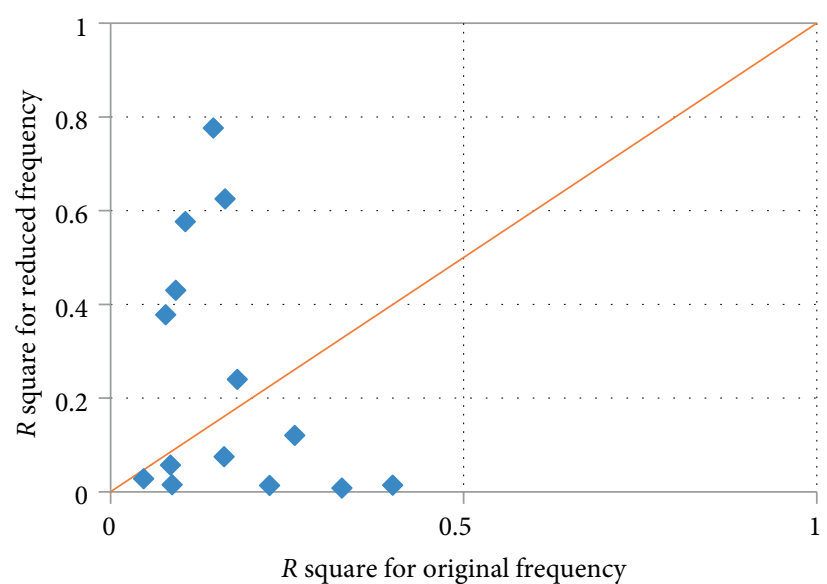

(a)

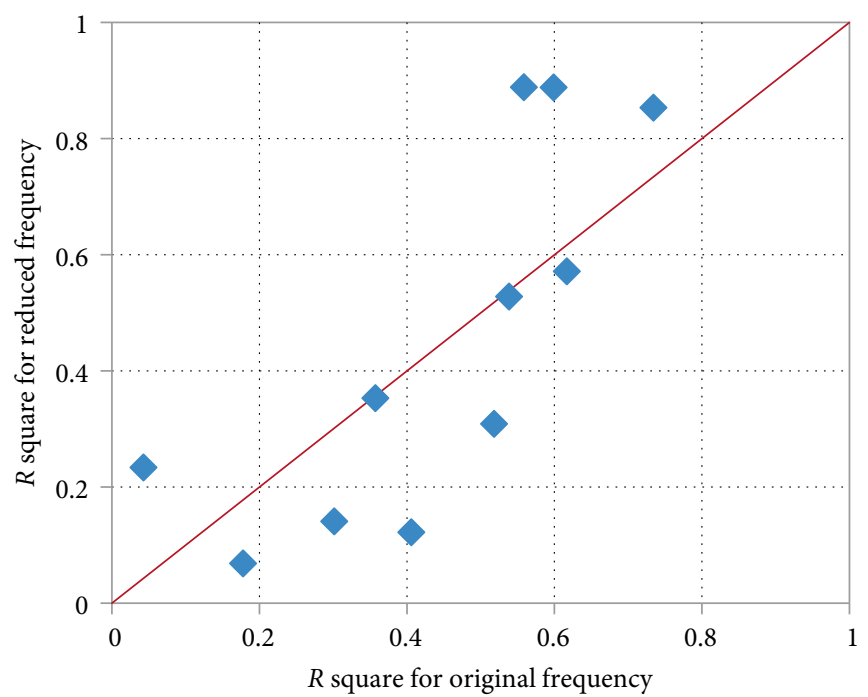

(c)

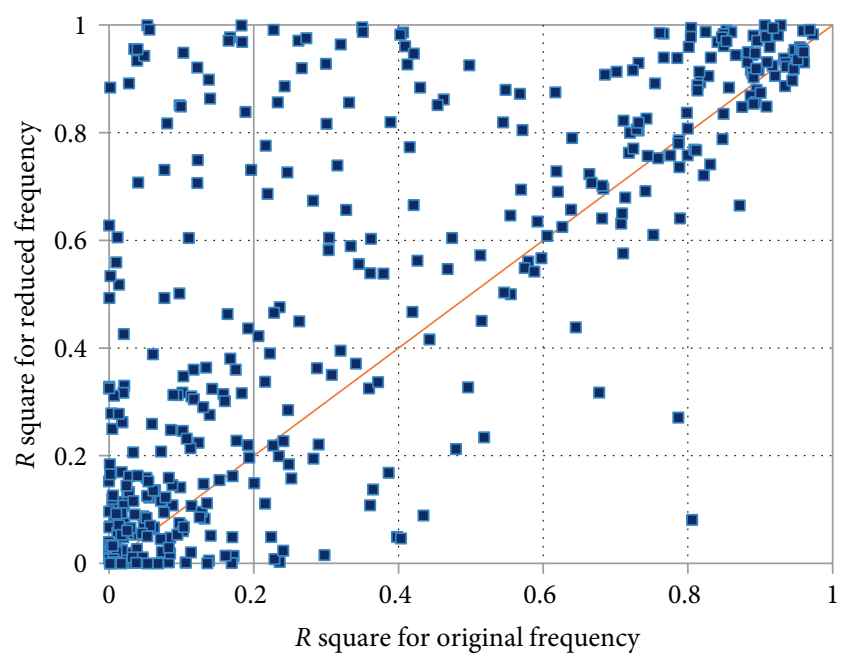

(e)

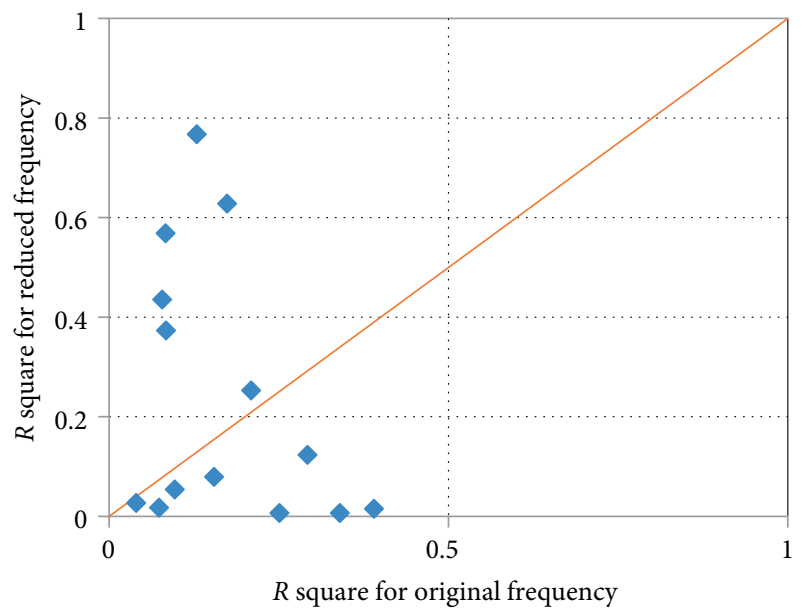

(b)

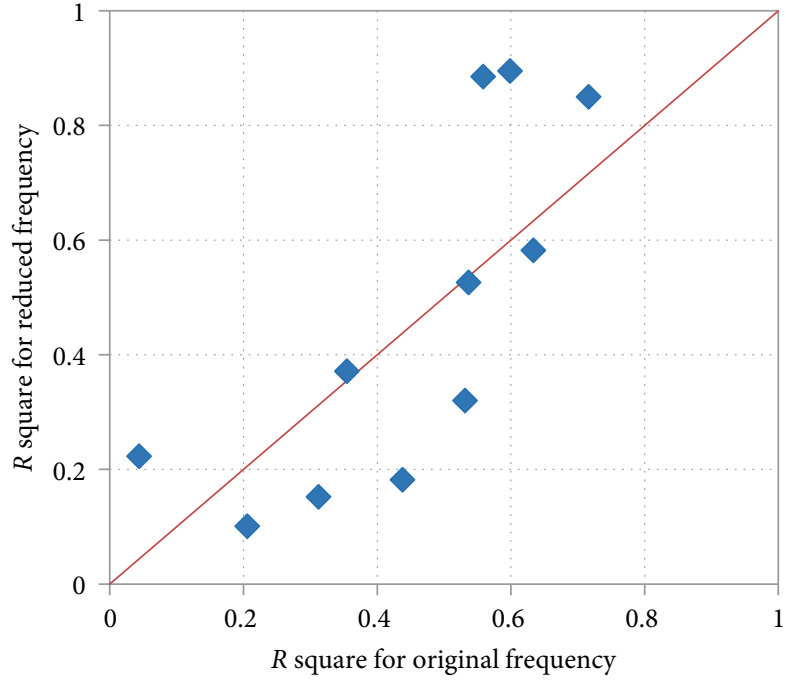

(d)

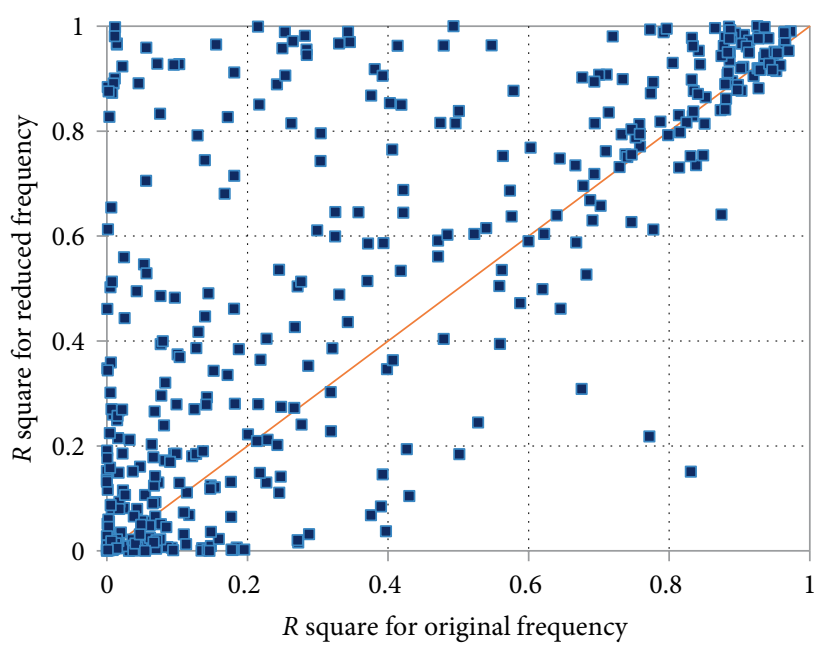

(f)

FIGURE 1: $R$ square of performance models for IRI ((a, b) are for urban roads, $(\mathrm{c}, \mathrm{d})$ are for highways, (e, $\mathrm{f})$ are for LTPP data). (a) Change of $R^{2}$ for linear model. (b) Change of $R^{2}$ for exponential model. (c) Change of $R^{2}$ for linear model. (d) Change of $R^{2}$ for exponential model. (e) Change of $R^{2}$ for linear model. (f) Change of $R^{2}$ for exponential model. 


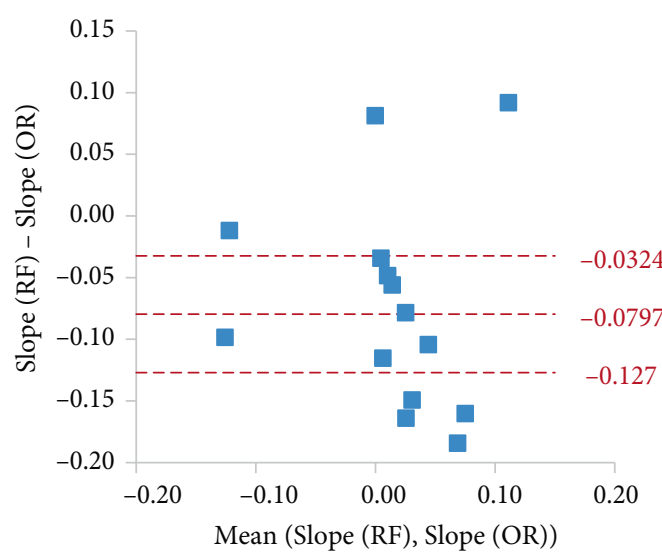

(a)

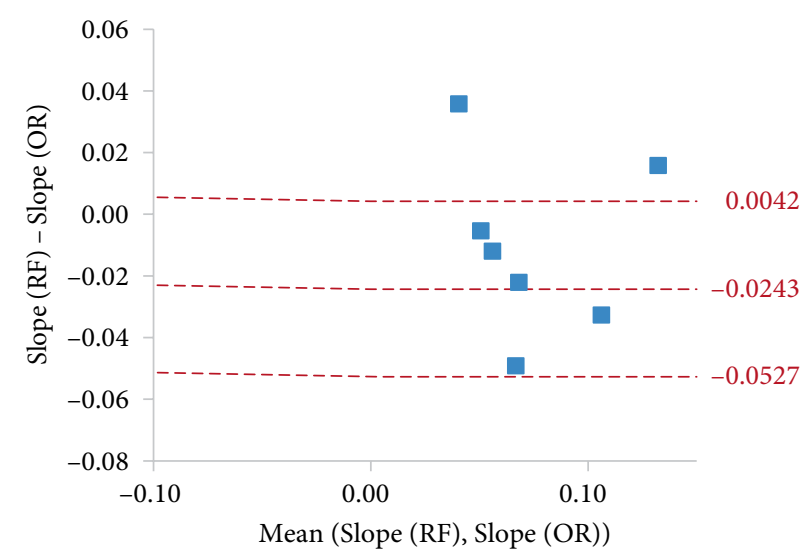

(b)

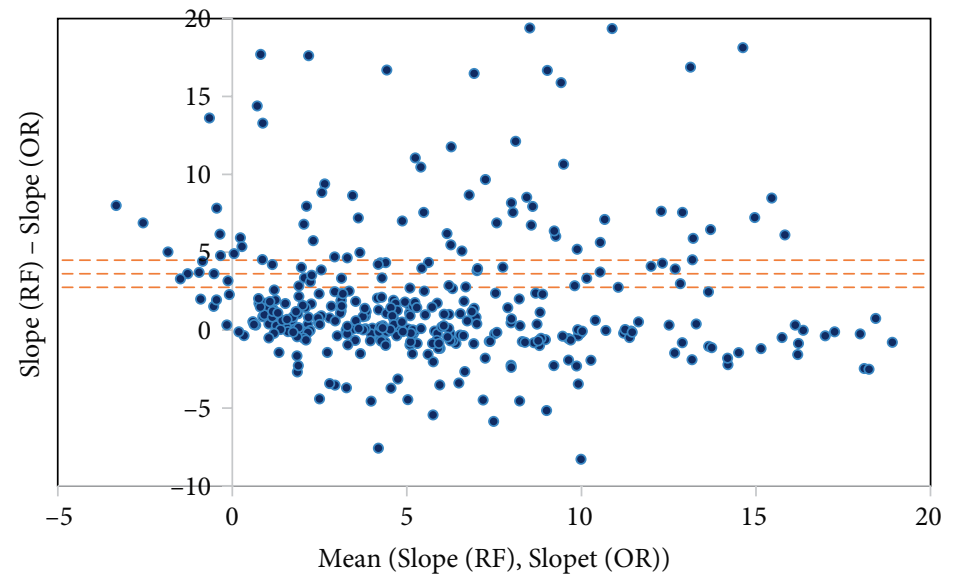

(c)

FIgURE 2: Matched pairs of slopes for IRI ((a) urban roads, (b) highways, and (c) LTPP data).

The reliability of performance model (RPM) of urban roads (Figure 4(a)) is more discrete than the RPM of highways (Figure 4(b)), which may be due to the higher frequency of routine maintenance on some specific roads or data errors due to survey condition.

3.4. Performance Deterioration Trend of PCI. Figures 5 and 6 illustrated the results of matched pair tests for the slopes and the intercepts of the linear models of PCI for original collection frequency and reduced collection frequency. The slope indicated the general trend of change of performance index. The average value of means, the average value of differences, the $95 \%$ upper bond and the $95 \%$ lower bond are marked with red dotted line in Figures 5 and 6.

Seen from Figures 5 and 6, results indicate that the slopes of the linear models determined by original collection frequency are not significantly lower than the slopes of the linear models determined by reduced collection frequency for both urban roads and highways. Since zero values are within $95 \%$ confident interval, the general deterioration rate of the performance model may be slightly changed by reducing the collection frequency.

However, there is possibility that the performance deterioration rates of urban roads are underestimated by decreasing the collection frequency (Figures 5(a) and 6(a)). With the deterioration trend underestimated, there might be delay of maintenance activities, so frequency of PCI data collection for main urban roads should not be reduced. The performance rate change of urban roads is more discrete than the performance rate change of highways, which also reflects the worse data quality of urban roads compared to highways.

\section{Discussions and Conclusions}

To evaluate the influence of different pavement monitoring frequencies on the accuracy of pavement performance models, 14 urban roads and 11 highways selected from PMSs of Shanghai and 404 road sections from LTPP database were investigated. The performance models with reduced monitoring frequencies and original frequencies were compared for the analysis. Based on the analyses above, several conclusions can be summarized as below:

(1) The influence of data collection frequency on the accuracy and preciseness of performance models depends on the variability of raw data. With low variability, the decrease of collection frequency may not necessarily affect the performance model. 


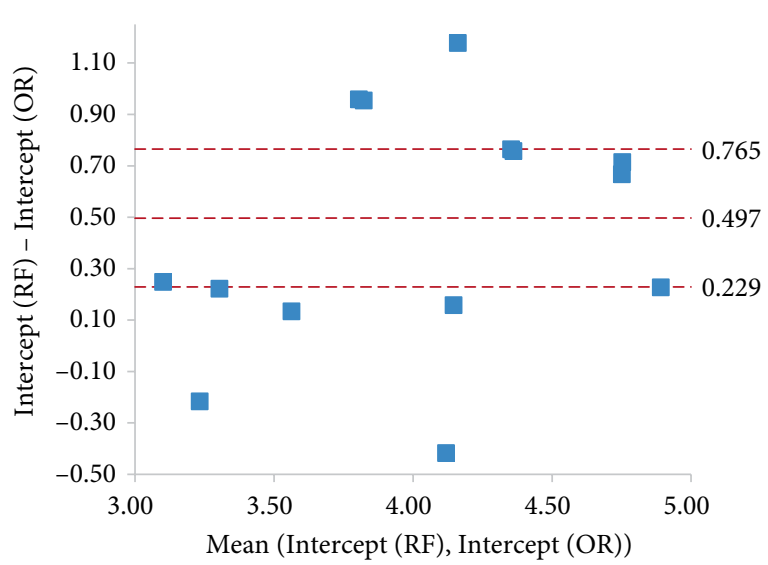

(a)

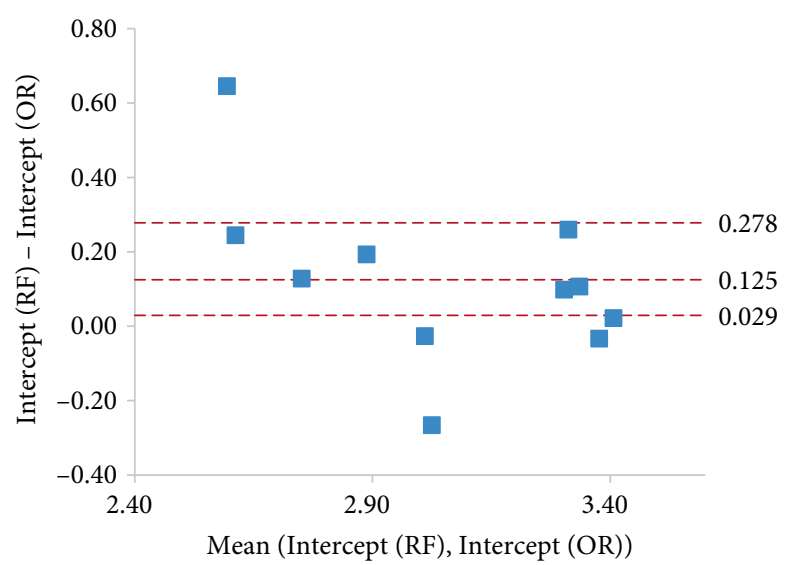

(b)

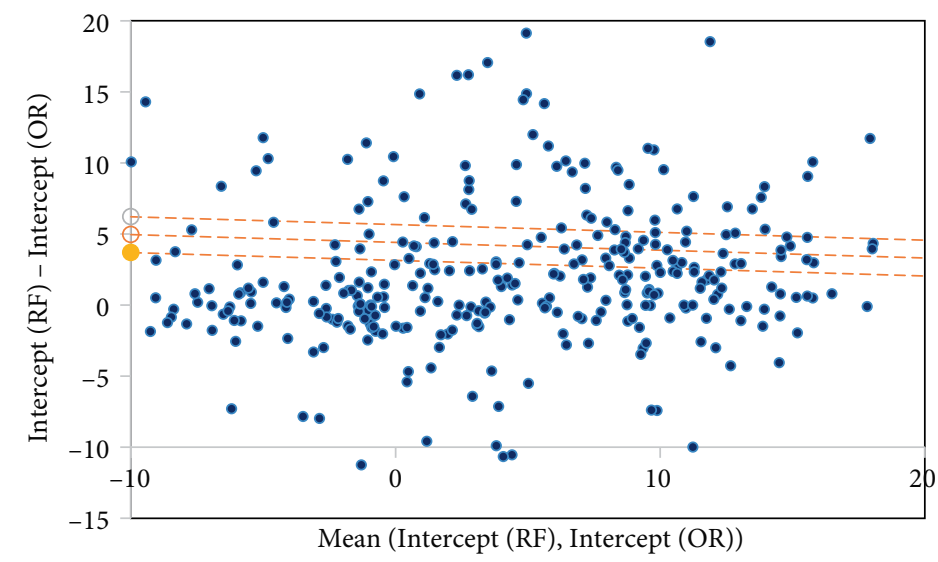

(c)

FIgURE 3: Matched pairs of intercept for IRI ((a) urban roads, (b) highways, and (c) LTPP data).

(2) For urban roads, performance model of PCI based on higher frequency is more proper for a certain project with clear maintenance history but may be inappropriate for net level management. And for performance model construction and evaluation on average condition in a certain area, data collection frequency can be reduced to 2-3 years.

(3) For both urban roads and highways, the decrease of collection frequency may underestimate the deterioration rates of IRI while may not necessarily influence the general trend of PCI of highways. Ensuring the data quality of PCI seems much more necessary than increasing the collection frequency for pavement performance models construction.

(4) The performance rates of IRI change of urban roads is more discrete than the performance rate change of highways, which is consistent with PCI. Besides, IRI data of urban roads seem unreliable in the time dimension, which means urban roads are not suitable for IRI model construction.

(5) Effect of frequency reduction on IRI models with higher values seems greater than on IRI models with lower values, which means collection frequency should be rescheduled according to pavement conditions.

(6) Comparing with IRI, PCI seems less sensitive to collection frequency. Therefore, a decrease of collection frequency for PCI of highways may be considered, more work should be done to ensure the PCI data quality, thus to guarantee the rationality of maintenance decisions. However, for a certain project, routine maintenance and condition indices data collection may need higher frequency.

This paper presented a comparative analysis of urban roads and highways, by analyzing the influence of collection frequency on the performance model based on historical data at the network level PMS application, to find the difference between urban roads and highways management. An increase in sample rates is necessary when the current data collection plan results in high variability of the performance model, whereas a decrease in sample rate is recommended when the general trend of the performance model is stable with low variability. One should also be aware that some of the findings in this paper are established based on datasets in certain area (Shanghai of China), which may not be applicable to other areas. 


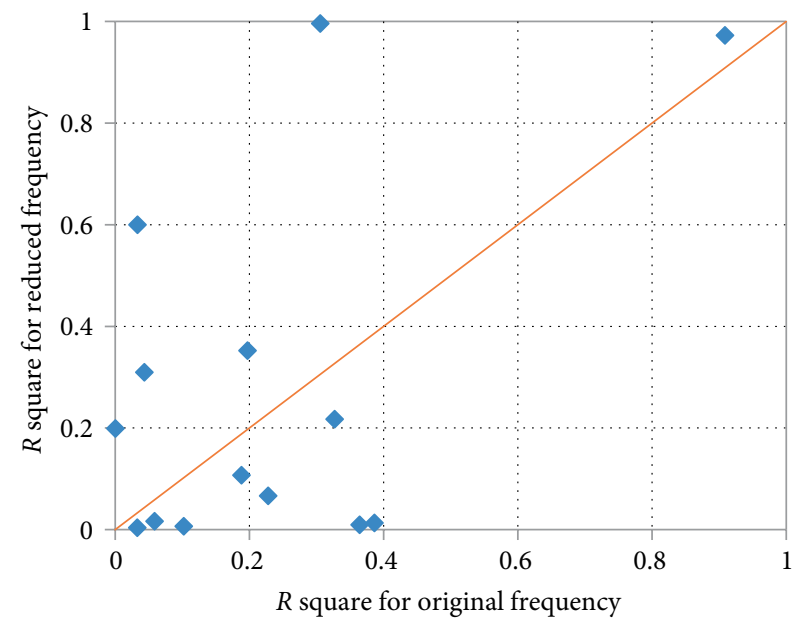

(a)

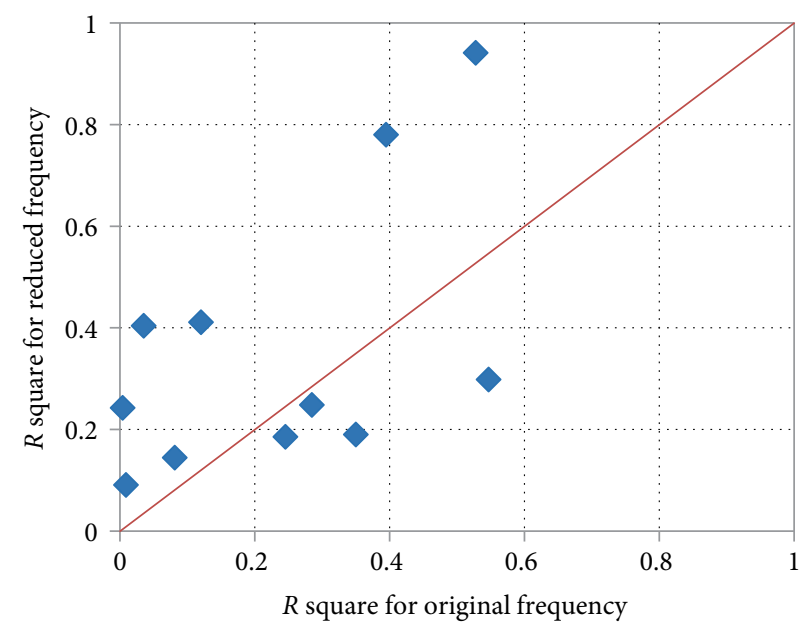

(c)

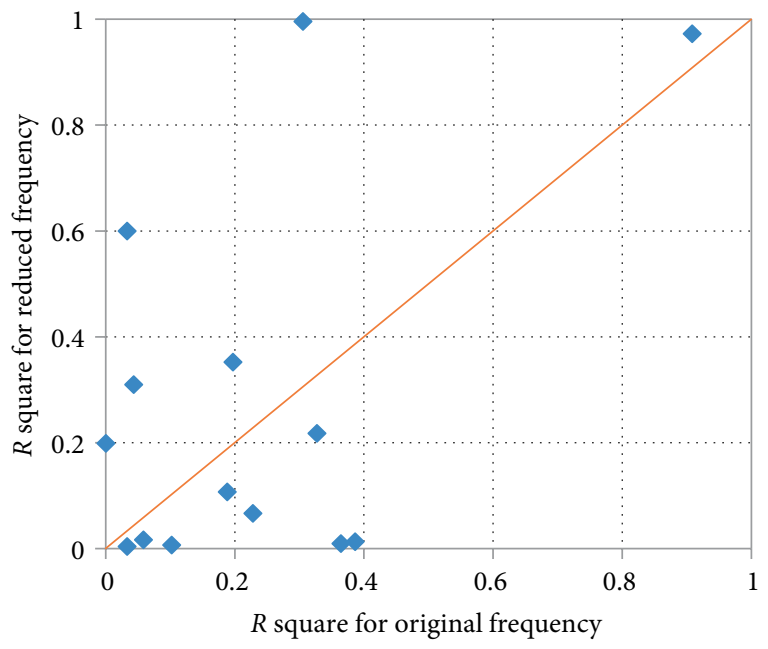

(b)

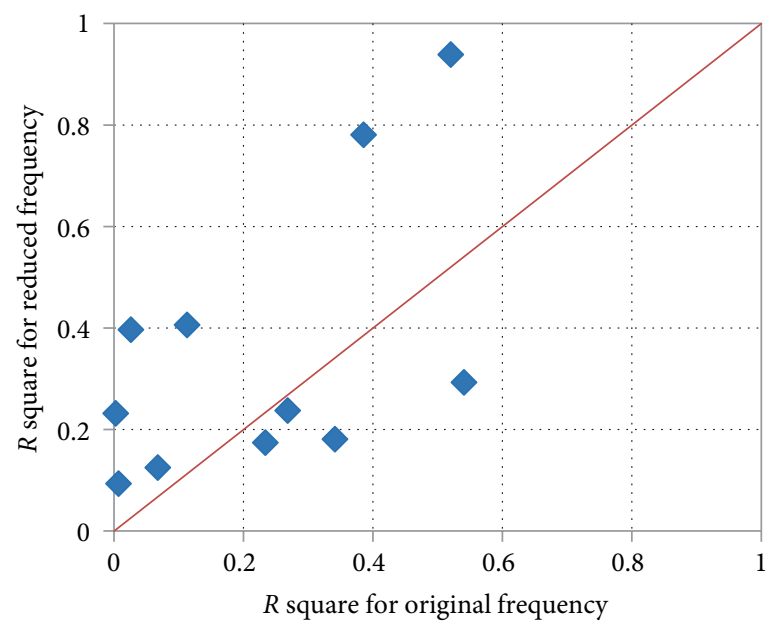

(d)

FigURE 4: Changes of $R^{2}$ for PCI performance models ( (a,b) are for urban roads, (c,d) are for highways). (a) Change of $R^{2}$ for linear model. (b) Change of $R^{2}$ for exponential model. (c) Change of $R^{2}$ for linear model. (d) Change of $R^{2}$ for exponential model.

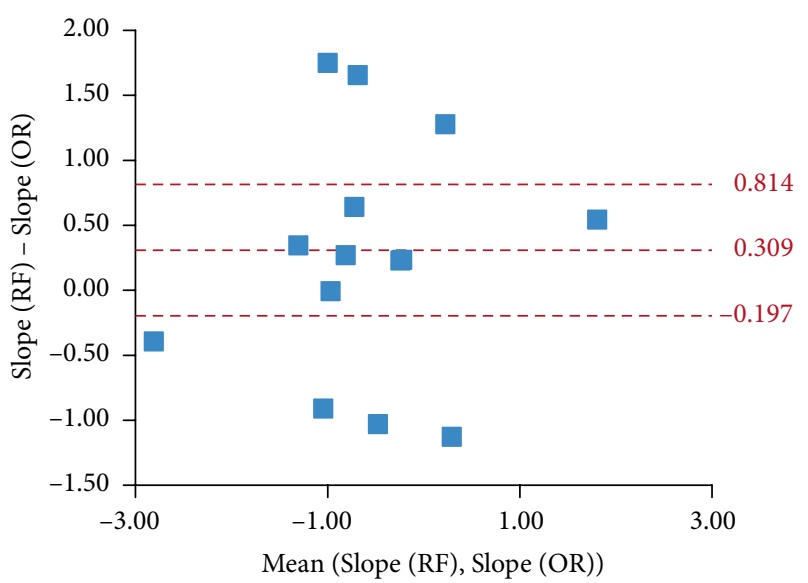

(a)

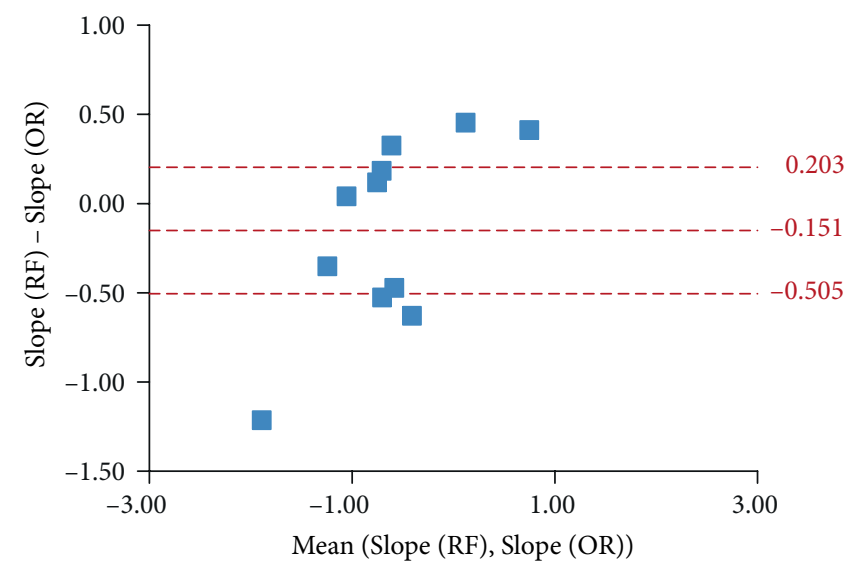

(b)

FIGURE 5: Matched pairs of slopes for PCI ((a) urban roads, (b) highways). 


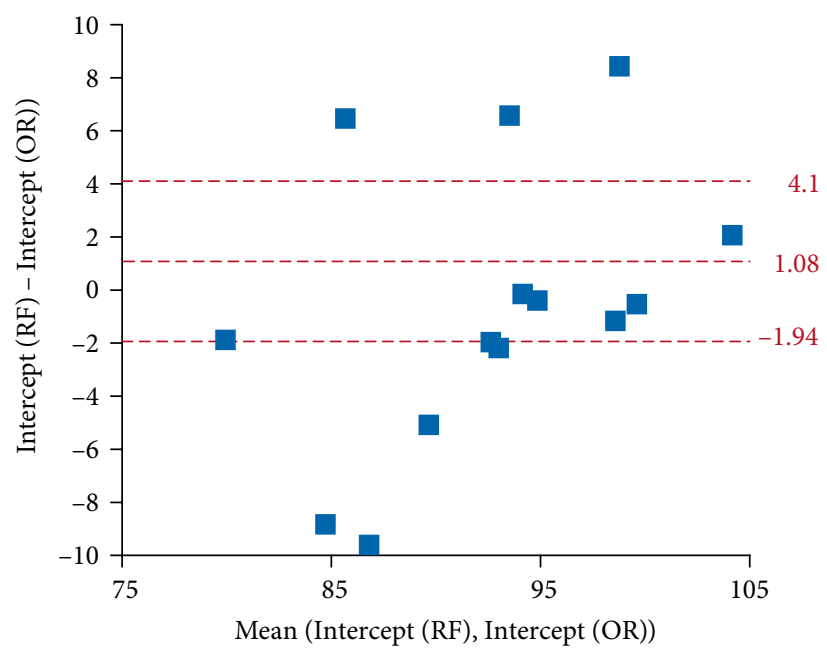

(a)

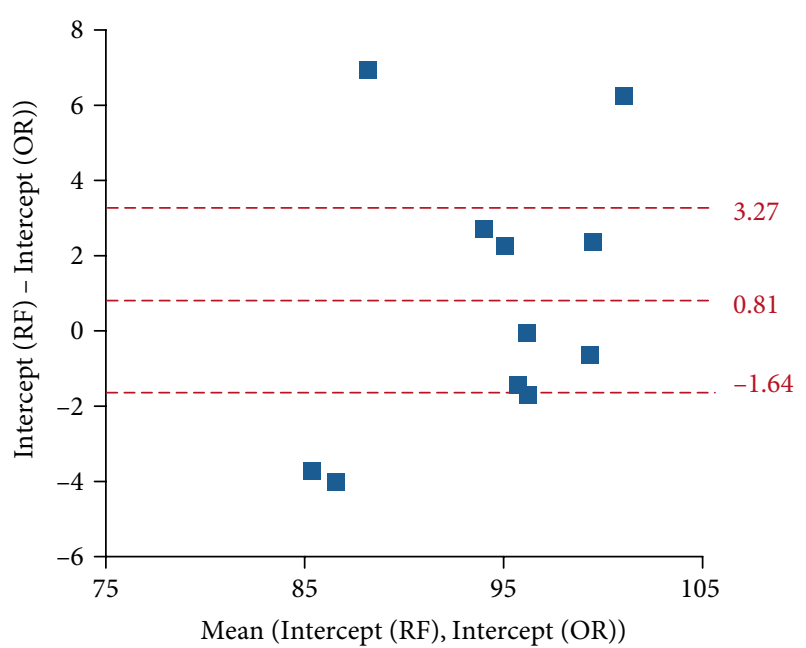

(b)

Figure 6: Matched pairs of intercept for PCI ((a) urban roads, (b) highways).

TABLE 2: PCI data of selected highways from 2003 to 2012.

\begin{tabular}{lccccccccccc}
\hline ID & Length $(\mathrm{km})$ & 2003 & 2004 & 2005 & 2006 & 2007 & 2008 & 2009 & 2010 & 2011 & 2012 \\
\hline S121310115 & 8.3 & 99.31 & 99.71 & 91.53 & 96.85 & 83.57 & 84.05 & 84.07 & 90.05 & 92.69 & 90.09 \\
X005310115 & 1.23 & 96.12 & 98.41 & 94.03 & 86.96 & 94.06 & 94.75 & 84.7 & 88.81 & 82.11 & 88.82 \\
X009310115 & 8.76 & 97.29 & 94.82 & 90.77 & 94.5 & 91.45 & 91.25 & 92.2 & 92.21 & 92.09 & 85.22 \\
X012310115 & 1.96 & 93.91 & 88.91 & 91.83 & 93.35 & 88.95 & 77.49 & 93.26 & 93.3 & 96.44 & 98.46 \\
X030310115 & 6.71 & & 99.74 & 97.06 & 95.15 & 86.97 & 88.76 & 88.23 & 88.24 & 94.21 & 89 \\
X572310115 & 5.44 & 99.71 & 98.11 & 91.82 & 84.94 & 87.23 & 91.59 & 94.34 & 92.41 & 92.28 & 85.62 \\
X574310115 & 10.95 & 97.38 & 97.83 & 90.81 & 78.07 & 90.7 & 90.59 & 85.91 & 92.67 & 91.62 & 92.2 \\
X579310115 & 2.4 & 84.11 & 85.89 & 92.61 & 74.89 & 83.82 & 80.01 & 85.59 & 85.62 & 87.19 & 82.09 \\
X581310115 & 7.1 & 99.46 & 95.63 & 89.54 & 87.51 & 89.91 & 89.5 & 86.88 & 91.72 & 91.11 & 93.92 \\
X583310115 & 2.63 & 86.32 & 88.97 & 79.2 & 90.93 & 88.75 & 90.91 & 85.19 & 85.2 & 86.78 & 84.38 \\
X585310115 & 0.78 & 100 & 97.4 & 100 & 100 & 88.72 & 92.8 & 92.01 & 92.02 & 97.06 & 92.02 \\
\hline
\end{tabular}


TABLE 3: IRI data of selected highways from 2003 to 2012.

\begin{tabular}{|c|c|c|c|c|c|c|c|c|c|c|c|}
\hline ID & $\begin{array}{c}\text { Length } \\
(\mathrm{km})\end{array}$ & 2003 & 2004 & 2005 & 2006 & 2007 & 2008 & 2009 & 2010 & 2011 & 2012 \\
\hline S121310115 & 8.3 & & 2.52 & & 3.693333 & 3.693333 & & 3.019304 & & & 4.336364 \\
\hline X005310115 & 1.23 & & 3.08 & 3.426667 & & 3.12 & 3.089049 & 3.609378 & 3.530563 & 3.279835 & 3.72066 \\
\hline X009310115 & 8.76 & 3.52 & 3.573333 & 3.52 & 3.853333 & 3.666667 & 3.47326 & 3.704663 & 3.889944 & 3.9275 & 4.247312 \\
\hline X012310115 & 1.96 & & 3.28 & 3.613333 & 2.906667 & & 2.830469 & 3.253322 & 3.752336 & 3.292099 & 3.440792 \\
\hline X030310115 & 6.71 & & 3.16 & 3.706667 & 4.533333 & 4.08 & 3.670862 & 3.81167 & 4.488043 & 3.517952 & 4.714134 \\
\hline X572310115 & 5.44 & 2.746667 & 3.16 & 4.04 & 4.093333 & 4.573333 & 2.540401 & 2.461172 & 2.588422 & 2.55262 & 4.419308 \\
\hline X574310115 & 10.95 & 2.653333 & 2.44 & 3.173333 & 2.946667 & 2.76 & 2.64748 & 2.620073 & 2.389876 & 2.341975 & \\
\hline X579310115 & 2.4 & & & 3.093333 & 3.56 & 4.826667 & 3.8845 & 4.305469 & 4.554118 & 4.89474 & \\
\hline X581310115 & 7.1 & 3.6 & 3.026667 & 3.746667 & 3.64 & 4.693333 & 3.130825 & 3.263966 & 3.213 & 3.125176 & 4.955572 \\
\hline X583310115 & 2.63 & 3.426667 & 4.4 & 4.186 & 3.12 & 4.413333 & 4.762715 & 4.43143 & 6.559752 & 5.305261 & 5.424 \\
\hline $\mathrm{X} 585$ & 0.78 & 2.133333 & 2.053 & 3.826 & & 4.226667 & 0 & 0 & 0 & 0 & \\
\hline X586310115 & 2.68 & 2.84 & 3.613333 & 4.746667 & 5.386667 & 4 & 2.573061 & 2.65869 & 2.920644 & 2.682524 & 2.856079 \\
\hline X587310115 & 0.84 & 2.973333 & 2.813333 & 4.24 & 7.053333 & 4.173333 & 2.954495 & 3.235367 & 3.129688 & 3.029497 & 3.005039 \\
\hline X588310115 & 1.34 & 2.773333 & 2.853333 & 3.68 & 3.96 & 4.693333 & 2.754958 & 3.019304 & 2.914613 & 2.87325 & 2.811456 \\
\hline X590310115 & & & & & & & & & & & \\
\hline X592310115 & 0.92 & 2.813333 & 2.88 & 3.573333 & 3.613333 & 3.986667 & 3.024804 & 2.789406 & 3.185038 & 2.849684 & 3.165012 \\
\hline X593310115 & 2.05 & 3.333333 & 3.173333 & 4.533333 & 4.333333 & 4.84 & 3.21815 & 2.9776 & 2.966932 & 3.263976 & 2.876831 \\
\hline X594310115 & 5.98 & 4.533333 & 4.773333 & 4.026667 & 4.106667 & 3.853333 & 0 & 0 & 0 & 0 & 4.181847 \\
\hline X595310115 & 2.23 & 3.013333 & 3.146667 & 3.546667 & 3.266667 & 2 & 2.540401 & & 2.588422 & & 2.895444 \\
\hline X601310115 & 7.36 & 3.506667 & 3.826667 & 5.053333 & 4.933333 & 4.92 & & 2.620073 & & 2.341975 & 2.645441 \\
\hline X603310115 & 4.5 & & 2.68 & 2.786667 & 2.693333 & 2.826667 & 2.661673 & 3.075913 & 2.188938 & 2.592863 & 2.530299 \\
\hline X611310115 & 7.07 & 2.053333 & 2.026667 & 2.346667 & 2.24 & 2.24 & 1.896011 & 1.842303 & 1.701961 & 1.985723 & 2.434594 \\
\hline X617310115 & 4.88 & 4.306667 & 4.44 & 5.066667 & 6 & 5.426667 & 3.494586 & 3.660918 & 3.668662 & 3.265904 & 3.451707 \\
\hline X619310115 & 1.85 & 3.32 & 3.533333 & 3.12 & 3.346667 & 3.373333 & 3.130825 & 3.263966 & 3.213851 & 3.125176 & 3.372739 \\
\hline X620310115 & 3.15 & 2.84 & 3.08 & 2.706667 & 3.04 & 2.826667 & 2.389876 & 2.350355 & 2.33185 & 2.426714 & 2.813535 \\
\hline X575310115 & 15.04 & 3.746667 & 4.346667 & 4.573333 & 4.92 & & 2.661673 & 3.075913 & 2.188938 & 2.592863 & 3.893995 \\
\hline X578310115 & 2.08 & 4.96 & 4.586667 & 5.866667 & 6.413333 & 6.573333 & 4.535089 & 4.690059 & 4.560434 & 4.804738 & 4.796962 \\
\hline
\end{tabular}

TABLE 4: PCI data of selected urban roads from 2003 to 2012.

\begin{tabular}{lccccccccc}
\hline Section number & Length $(\mathrm{m})$ & 2010 & 2011 & 2012 & 2013 & 2014 & 2015 & 2016 & 2017 \\
\hline JAS000004325 & 422 & 94 & 98 & 89.44 & 87.65 & 98 & 93.03 & 85.95 & 95.5 \\
JAS000004441 & 238 & 96 & 98 & 98 & 98 & 94.67 & 89.99 & 83.17 & 98 \\
HPS000010501 & 83 & 98 & 98 & 98 & 98 & 98 & 86.66 & 92.39 & 95.31 \\
HPS000010493 & 85 & 92 & 94.67 & 91 & 91.47 & 98 & 87.49 & 80.29 & 91.49 \\
HKS000003011 & 670 & 80.34 & 80.31 & 82.66 & 98 & 85.83 & 91.1 & 91.42 & 80.8 \\
HKS000003029 & 245 & 89.67 & 90.18 & 81.85 & 98 & 93.33 & 94.54 & 91.09 & 84.74 \\
XHS000007879 & 186 & 98 & 87.69 & 88 & 94.33 & 85 & 88.32 & 85.98 & 95.46 \\
XHS000007880 & 323 & 89.09 & 82.84 & 73.99 & 87.78 & 93.67 & 91.5 & 88.03 & 95.45 \\
CNS000000899 & 575 & 98 & 92.53 & 87 & 91.2 & 94.33 & 87.39 & 92.77 & 92.96 \\
CNS000000821 & 364 & 98 & 98 & 75.55 & 98 & 89.44 & 98 & 90.33 & 88 \\
YPS000014463 & 319 & 98 & 79.36 & 79 & 78.52 & 74.47 & 84.29 & 75.47 & 76.61 \\
YPS000014411 & 492 & 91.77 & 81.65 & 88 & 98 & 98 & 87.91 & 76.93 & 77.47 \\
YPS000014328 & 439 & 94 & 79.54 & 91 & 85.27 & 86.42 & 85.74 & 76.18 & 80.34 \\
YPS000013433 & 440 & 98 & 98 & 98 & 95 & 87.96 & 87.13 & 86.43 & 80.59 \\
\hline
\end{tabular}


TABLE 5: IRI data of selected urban roads from 2003 to 2012.

\begin{tabular}{lcccccccccc}
\hline Section number & Length $(\mathrm{m})$ & 2010 & 2011 & 2012 & 2013 & 2014 & 2015 & 2016 & 2017 \\
\hline JAS000004325 & 422 & 2.58 & 4.29 & 3.93 & 4.17 & 4.3 & 4.4 & 4.35 & 4.18 \\
JAS000004441 & 238 & 3.17 & 3.09 & 2.87 & 3.27 & 3.31 & 3.26 & 4.17 & 3 \\
HPS000010501 & 83 & 4.29 & 4.91 & 3.6 & 4.34 & 3.36 & 3.75 & 4.22 & 3.94 \\
HPS000010493 & 85 & 4.24 & 4.85 & 4.49 & 5.36 & 4.53 & 5.08 & 5.37 & 4.89 \\
HKS000003011 & 670 & 4.93 & 3.62 & 3.74 & 6.44 & 3.98 & 3.73 & 3.93 & 3.67 \\
HKS000003029 & 245 & 3.1 & 5.18 & 5.25 & 3.94 & 5.16 & 4.55 & 5.65 & 4.82 \\
XHS000007879 & 186 & 3.77 & 3.73 & 3.18 & 3.48 & 3.24 & 3.74 & 3.25 & 4.69 \\
XHS000007880 & 323 & 3.11 & 3.4 & 2.99 & 3.38 & 3.61 & 3.28 & 3.21 & 3.35 \\
CNS000000899 & 575 & 4.24 & 4.29 & 3.91 & 4.24 & 4.38 & 3.72 & 4.9 & 4.37 \\
CNS000000821 & 364 & 3.79 & 3.46 & 3.34 & 3.87 & 3.36 & 3.38 & 4.48 & 3.53 \\
YPS000014463 & 319 & 3.78 & 4.58 & 3.55 & 4.66 & 4.38 & 4.32 & 4.45 & 4.35 \\
YPS000014411 & 492 & 4.71 & 3.91 & 4.28 & 4.24 & 3.56 & 4.06 & 4.15 & 4.24 \\
YPS000014328 & 439 & 2.97 & 4.01 & 3.31 & 4.55 & 3.7 & 3.79 & 4.26 & 3.97 \\
YPS000013433 & 440 & 3.16 & 4.42 & 3.09 & 4.9 & 4.21 & 4.31 & 4.12 & 4.24 \\
\hline
\end{tabular}

\section{Appendix}

Data table from PMS. See Tables 2-5.

\section{Data Availability}

Some of the data used to support the findings of this study are included within the paper, and some of the data used to support the findings of this study are from LTTP data as the attachment "Bucket_30271."

\section{Conflicts of Interest}

The authors declare that they have no conflicts of interest.

\section{Funding}

This work was supported by the National Natural Science Foundation of China under Grant 51708065; and Central College Project of Chongqing University under Grant 106112017 CDJXY200006.

\section{Supplementary Materials}

The attachment file is the IRI data selected from LTPP database, and the data screening principle is within the paper, as follows: We selected 2922 road sections in LTPP database to study this influence on IRI, 2518 sections unable to reflect performance decay are removed as IRI value has been below two throughout the data collection cycle or the amount of data is less than three. (Supplementary Materials)

\section{References}

[1] K. H. McGhee, NCHRP Synthesis 334: Automated Pavement Distress Collection Techniques, Transportation Research Board, Washington, DC, USA, 2004.
[2] M. Hafez, K. Ksaibati, and R. Anderson-Sprecher, "Utilizing statistical techniques in estimating uncollected pavementcondition data," Journal of Transportation Engineering, vol. 142, no. 12, p. $04016065,2016$.

[3] J. N. Meegoda and S. Gao, "Roughness progression model for asphalt pavements using long-term pavement performance data," Journal of Transportation Engineering, vol. 140, no. 8, p. $4014037,2014$.

[4] M. Mazari and D. D. Rodriguez, "Prediction of pavement roughness using a hybrid gene expression programmingneural network technique," Journal of Traffic and Transportation Engineering (English Edition), vol. 3, no. 5, pp. 448-455, 2016.

[5] G. Kelly, D. Delaney, G. Chai, and S. Mohamed, "Optimising local council's return on investment from annual pavement rehabilitation budgets through targeting of the average pavement condition index," Journal of Traffic and Transportation Engineering (English Edition), vol. 3, no. 5, pp. 465-474, 2016.

[6] U. Kırbaş and M. Karaşahin, "Performance models for hot mix asphalt pavements in urban roads," Construction and Building Materials, vol. 116, pp. 281-288, 2016.

[7] T. I. Al-Suleiman and A. M. S. Shiyab, "Prediction of pavement remaining service life using roughness data-case study in Dubai," International Journal of Pavement Engineering, vol. 4, no. 2, pp. 121-129, 2003.

[8] S. W. Haider, G. Y. Baladi, K. Chatti, and C. M. Dean, "Effect of frequency of pavement condition data collection on performance prediction," Transportation Research Record, vol. 2153, no. 1, pp. 67-80, 2018.

[9] S. Saliminejad and N. G. Gharaibeh, "Impact of error in pavement condition data on the output of network-level pavement management systems," Transportation Research Record, vol. 2366, no. 1, pp. 110-119, 2018.

[10] T. Chopra, M. Parida, N. Kwatra, and J. Mandhani, "Development of pavement maintenance management system (PMMS) of urban road network using HDM-4 model," International Journal of Engineering \& Applied Sciences, vol. 9, no. 1, p. 14, 2017.

[11] M. Hafez, K. Ksaibati, and R. Atadero, "Best practices to support and improve pavement management systems for low-volume paved roads," International Journal of Pavement Engineering, vol. 20, no. 5, pp. 592-599, 2017. 
[12] G. Flintsch and K. K. Mcghee, NCHRP Synthesis 401: Quality Management of Pavement Condition Data Collection (A Synthesis of Highway Practice), Transportation Research Board of the National Academies, Washington, DC, USA, 2008.

[13] K. Park, N. E. Thomas, and K. Wayne Lee, "Applicability of the international roughness index as a predictor of asphalt pavement condition," Journal of Transportation Engineering, vol. 133, no. 12, pp. 706-709, 2007.

[14] Q. Dong, B. Huang, and S. Richards, "Calibration and application of treatment performance models in a pavement management system in Tennessee," Journal of Transportation Engineering, vol. 141, no. 2, p. 04014076, 2014.

[15] D. K. Merritt, G. K. Chang, and J. L. Rutledge, "Best practices for achieving and measuring pavement smoothness, a synthesis of state-of-practice (Report no. FHWA, LA.14, 550)," The Transtec Group Inc, Austin, TX, USA, 2015.

[16] H. Gong, Q. Dong, B. Huang, and X. Jia, "Effectiveness analyses of flexible pavement preventive maintenance treatments with LTPP SPS-3 experiment data," Journal of Transportation Engineering, vol. 142, no. 2, p. 04015045, 2015.

[17] K. Ahlin and N. O. J. Granlund, "Relating road roughness and vehicle speeds to human whole body vibration and exposure limits," International Journal of Pavement Engineering, vol. 3, no. 4, pp. 207-216, 2002.

[18] M. Sayers and T. D. Gillespie, "Guidelines for the conduct and calibration of road roughness measurements. World Bank Technical Report, no. UMTRI-84-13," The World Bank, Washington, DC, USA, 1984.

[19] P. Mucka and O. Kropac, "Sensitivity of road unevenness indicators to road waviness," Journal of Testing and Evaluation, vol. 37, no. 2, pp. 139-149, 2005.

[20] O. Kropáč and P. Múčka, "Classification scheme for random longitudinal road unevenness considering road waviness and vehicle response," Shock and Vibration, vol. 16, no. 3, pp. 273-289, 2009.

[21] O. Kropáč and P. Múčka, "Effect of obstacles in the road profile on the dynamic response of a vehicle," Proceedings of the Institution of Mechanical Engineers, Part D: Journal of Automobile Engineering, vol. 222, no. 3, pp. 353-370, 2008.

[22] O. Kropáč and P. Múčka, "Be careful when using the international roughness index as an indicator of road unevenness," Journal of Sound and Vibration, vol. 287, no. 4-5, pp. 989-1003, 2005.

[23] P. Múčka and J. Granlund, "Is the road quality still better?" Journal of Transportation Engineering, vol. 138, no. 12, pp. 1520-1529, 2012.

[24] S. Haider, G. Y. Baladi, K. Chatti, and C. M. Dean, "Effect of frequency of pavement condition data collection on performance prediction," Transportation Research Record: Journal of the Transportation Research, vol. 2153, no. 1, pp. 67-80, 2010.

[25] Y. Xu and Y. J. Tsai, "Effect of pavement condition monitoring frequency with unequal interval on determining pavement service life," in 91st Transportation Research Board TRB, National Research Council, Washington, DC, USA, 2012.

[26] Y. Xu, J. He, J. Ji, and S. Xu, "Effect of pavement condition monitoring frequency with unequal interval on determining pavement service life," Advances in Civil Engineering Materials, vol. 7, no. 2, pp. 261-271, 2018.

[27] L. Sun, Transportation Infrastructure Management System: Theory and Practice, China Communication Press, Beijing, 2009.
[28] M. W. Sayers and S. M. Karamihas, The Little Book of Profiling, University of Michigan Transportation Research Institute, Michigan, MI, USA, 1998. 


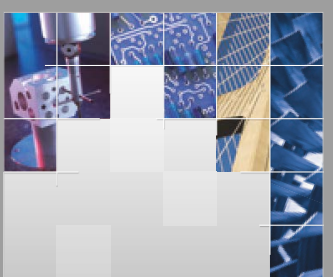

\section{Enfincering}
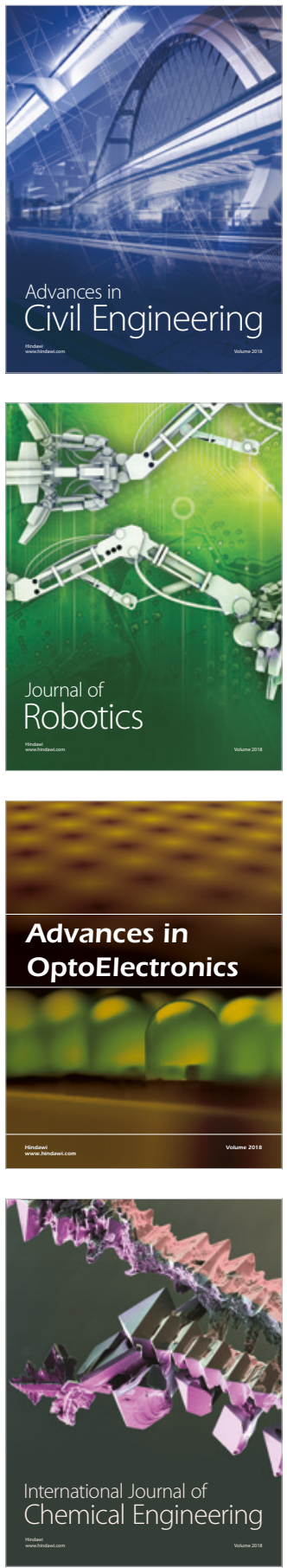

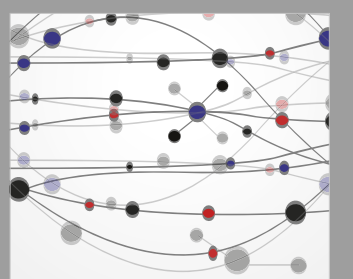

\section{Rotating \\ Machinery}

The Scientific World Journal

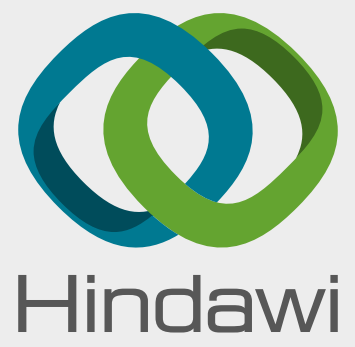

Submit your manuscripts at

www.hindawi.com
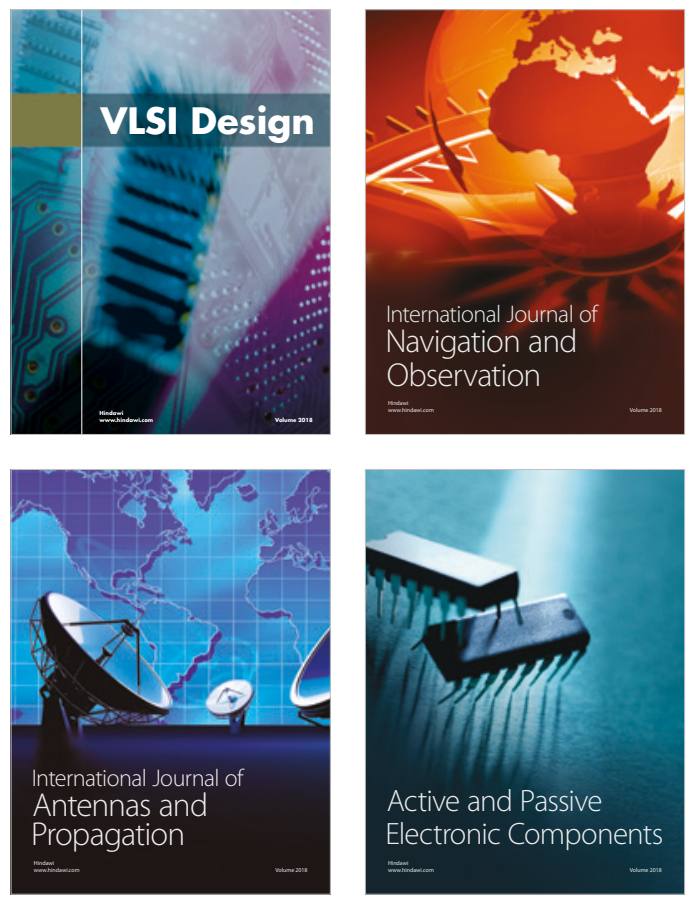
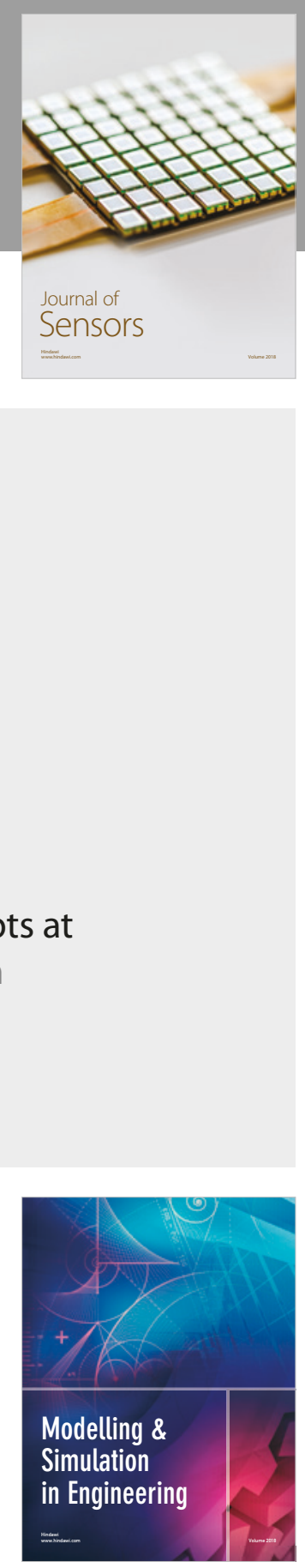

\section{Advances \\ Multimedia}
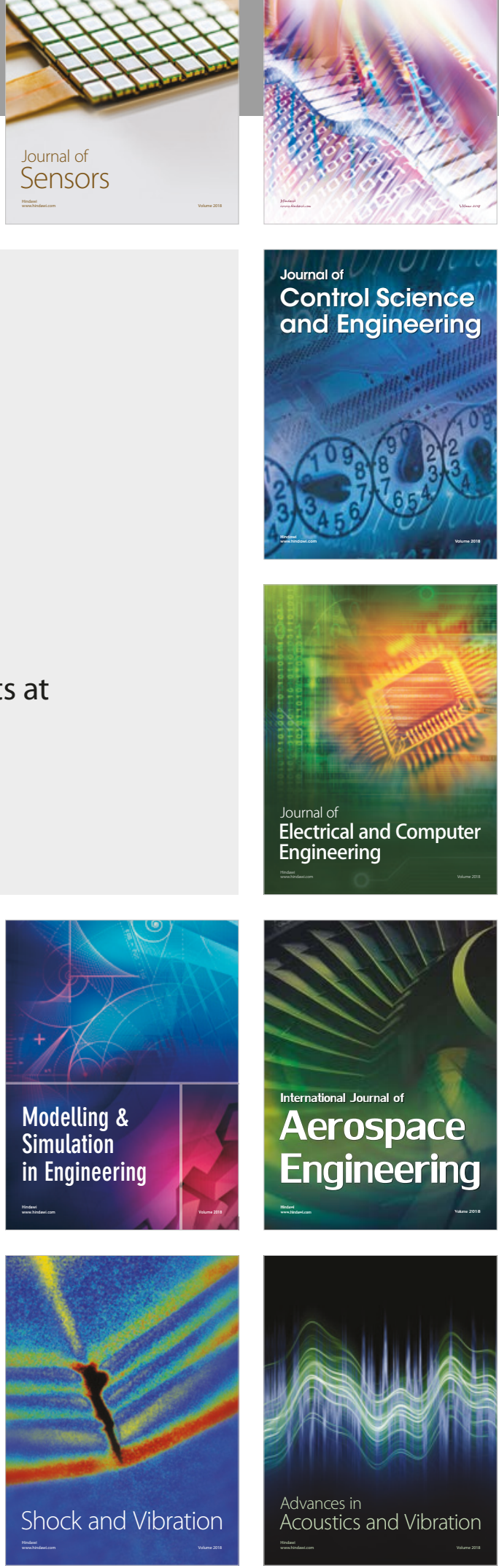